\title{
Hysteroscopic Findings Related with the Assessment and Treatment of Uterine Florid Cystic Endosalpingiosis: A Case Report and Review of All the Published Cases
}

\author{
Achados Histeroscópicos Incomuns Relacionados com \\ a Avaliação e Tratamento da Endossalpingiose Cística \\ Florida do Útero: Um Relato de Caso e Revisão de Todos \\ os Casos Publicados
}

\author{
Catarina PEIXINHO ${ }^{1}$, Raquel MACHADO-NEVES ${ }^{2}$, Pedro Tiago SILVA ${ }^{1}$, João BERNARDES ${ }^{1,3}$, Ana Catarina SILVA ${ }^{4}$, \\ Teresina AMARO ${ }^{2}$ \\ Acta Med Port 2021 Dec;34(12):868-873 - https://doi.org/10.20344/amp.14292
}

\section{ABSTRACT}

Introduction: Endosalpingiosis is a rare benign condition characterized by the presence of tubal epithelium outside the Fallopian tube. The clinical presentation of endosalpingiosis is nonspecific, and the diagnosis is typically incidental in women undergoing surgery for pelvic pain, infertility, urinary symptoms, or a pelvic mass. It can only be confirmed with histopathological examination.

Case Report: We report the first case of uterine florid cystic endosalpingiosis, with unusual hysteroscopic findings. We reviewed all the published cases of uterine florid cystic endosalpingiosis and their clinical presentation including hysteroscopic characteristics. It is a rare benign condition, with only 32 cases described in the literature. This is the first hysteroscopic description of this condition to be made.

Discussion: The patient first underwent a hysteroscopy and a leiomyoma resection when she was 51 -year-old. At 55 , she went through another hysteroscopy, and a polypoid lesion was excised. A third hysteroscopy, one year later, revealed a new polypoid lesion in a similar location. After the initial incisions, this polypoid lesion disappeared. By decreasing the intrauterine pressure, it became visible again, corresponding histologically to an endometrial polyp with tubal metaplasia. At last, she underwent a laparoscopic hysterectomy with a final histopathological diagnosis of uterine florid cystic endosalpingiosis.

Conclusion: Florid cystic endosalpingiosis is a rare condition that may be associated with several bizarre hysteroscopic findings.

Keywords: Fallopian Tube Diseases/diagnosis; Fallopian Tube Diseases/therapy; Gynecologic Surgical Procedures

\section{RESUMO}

Introdução: A endossalpingiose é uma condição benigna rara caracterizada pela presença de epitélio tubário fora da trompa de Falópio. A apresentação clínica da endossalpingiose é inespecífica e o diagnóstico é geralmente incidental em mulheres submetidas a cirurgia por dor pélvica, infertilidade, sintomas urinários ou massa pélvica. O diagnostico só pode ser confirmado com exame histopatológico.

Caso Clínico: Relatamos o primeiro caso de endosalpingiose cística florida uterina, no qual se encontrou achados histeroscópicos incomuns. Foram revistos todos os casos publicados de endosalpingiose cística florida uterina e suas apresentações clínicas, incluindo características histeroscópicas. Trata-se de uma condição benigna rara, com apenas 32 casos descritos na literatura. Apresentamos a primeira descrição histeroscópica desta patologia.

Discussão: A doente foi submetida a uma primeira histeroscopia e resseção de leiomioma aos 51 anos de idade. Com 55, realizou uma nova histeroscopia e removeu uma lesão polipóide. Uma terceira histeroscopia, um ano depois, revelou uma nova lesão polipóide num local semelhante. Após as incisões iniciais, essa lesão polipóide desapareceu. Ao diminuir a pressão intrauterina, tornou-se visível novamente, correspondendo histologicamente a um pólipo endometrial com metaplasia tubária. A doente foi submetida a uma histerectomia laparoscópica com diagnóstico histopatológico final de endosalpingiose cística florida uterina. Foram revistos todos os casos publicados de endosalpingiose cística florida uterina e suas apresentações clínicas, incluindo características histeroscópicas. Conclusão: A endosalpingiose cística florida uterina é uma condição rara que pode estar associada a achados histeroscópicos bizarros.

Palavras-chave: Doenças da Trompa de Falópio/diagnóstico; Doenças da Trompa de Falópio/tratamento; Procedimentos Cirúrgicos em Ginecologia

\section{INTRODUCTION}

Endosalpingiosis is a rare benign condition characterized by the presence of tubal epithelium outside the Fallopian tube. ${ }^{1}$ Endosalpingiosis has been found in the uterus, peritoneum, subperitoneal tissues, omentum, retroperitoneal no-

des, bowel, appendix, and, seldom, in the bladder. ${ }^{2}$ In analogy with endometriosis, some researchers have attributed endosalpingiosis to the ectopic implantation of Müllerian tissue within organs during pelvic surgery, namely, tubal

1. Department of Gynaecology and Obstetrics. Hospital Pedro Hispano. Matosinhos. Portugal.

2. Department of Pathology. Hospital Pedro Hispano. Matosinhos. Portugal.

3. Department of Gynaecology and Obstetrics. Faculty of Medicine. Universidade do Porto. Porto. Portugal.

4. Department of Radiology. Hospital Pedro Hispano. Matosinhos. Portugal.

$\triangle$ Autor correspondente: Catarina Peixinho. catarina.peixinho1989@gmail.com

Recebido: 08 de junho de 2020 - Aceite: 26 de agosto de 2020 - First published: 29 de fevereiro de 2020 - Online issue published: 02 de dezembro de 2021 Copyright $\odot$ Ordem dos Médicos 2021 
ligation, caesarean section or other uterine and abdominal surgery. ${ }^{3,4}$ However, the most accepted pathogenesis for endosalpingiosis is metaplastic change of coelomic cells into tubal-like epithelium. ${ }^{1}$ The metaplastic theory may explain why some cases have been reported in the absence of gynaecological diseases or surgical history and the reason why lesions may have multiple Müllerian components reflecting lesion differentiation. ${ }^{5}$

Endosalpingiosis has been associated with endometriosis or endocervicosis, although it often appears alone. It differs histologically from endometriosis in that it has a ciliated glandular epithelium and no endometrial stroma. Macroscopically, it often appears as a polypoid or as multiple cystic masses of different sizes.

The clinical presentation of endosalpingiosis is nonspecific, and the diagnosis is typically incidental in women undergoing surgery for pelvic pain, infertility, urinary symptoms, or a pelvic mass. The most common symptoms are pelvic pain, dysmenorrhea, abnormal uterine bleeding, and infertility. It can manifest as peritoneal nodular changes, omental or pelvic masses that can mimic malignancies. ${ }^{3}$ It always represents a diagnostic challenge that can only be confirmed with histopathological examination. ${ }^{2}$

We report the first case of uterine florid cystic endosalpingiosis (FCE), associated with an intrauterine leiomyoma and polyp, with hysteroscopic pitfalls.
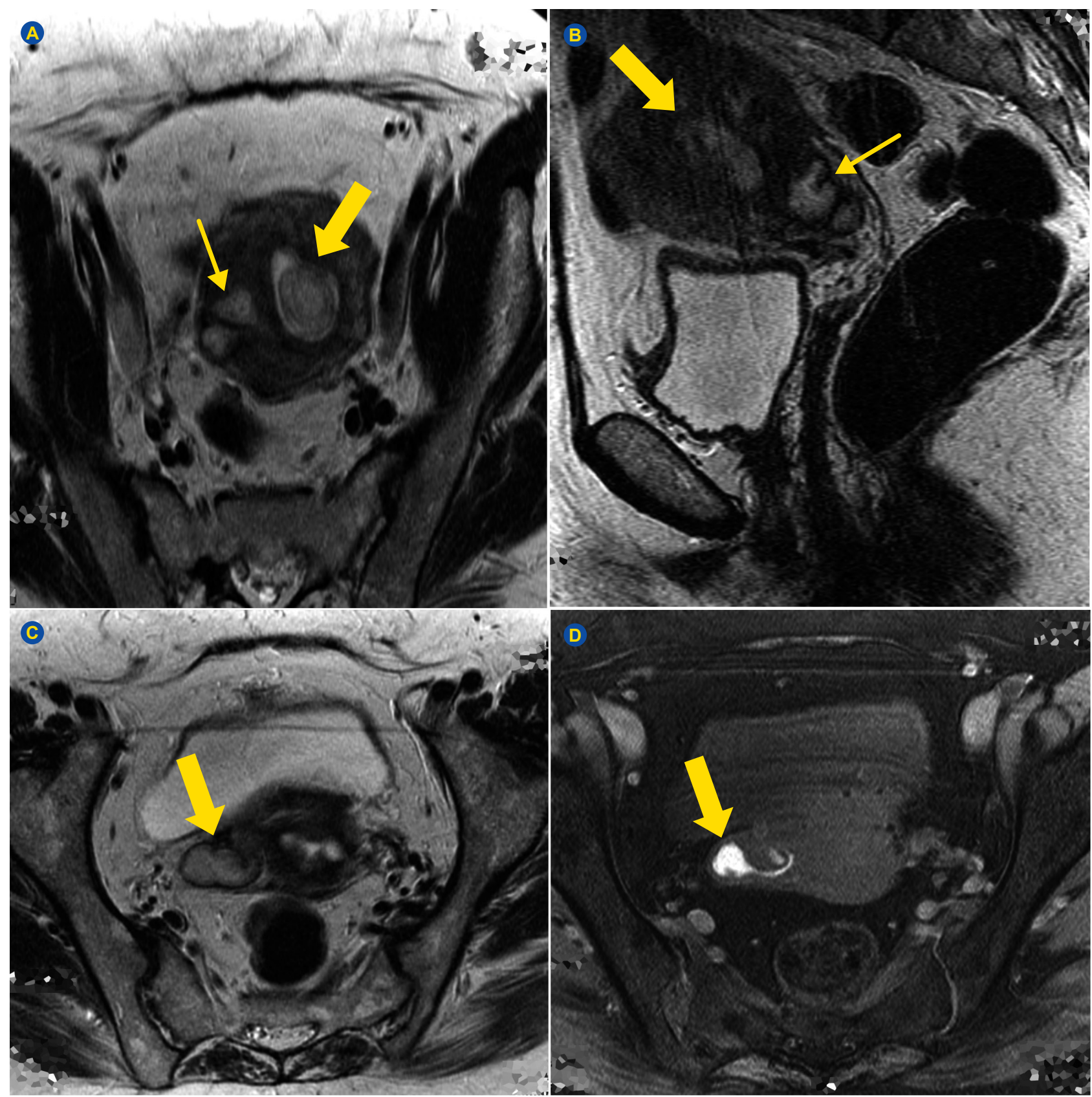

Figure 1 - Pelvic MRI. (A) Axial T2 WI shows a polypoid lesion in the uterine cavity (large arrow). (B) In the right lateral uterine wall, a hyperintense serpiginous lesion is also seen (fine arrow) better demonstrated in the sagittal T2 WI. Pelvic MRI Axial T2 (C) WI and Axial fat-sat T1 (D) in the same plane reveals that the serpiginous intramural uterine lesion has a hyperintense SI at the T1 fat-sat WI. This is compatible with haematic content, suggestive of co-existing pelvic endometriosis. 


\section{CASE REPORT}

A 51-year-old was referred to our hospital with perimenopausal bleeding. A pelvic ultrasound was performed. The ultrasound revealed a hyperechoic collection, which was judged to be in the endometrial cavity and an intracavitary lesion was identified. A pelvic MRI was requested to elucidate these unusual findings. A $33 \mathrm{~mm}$ intrauterine polypoid lesion, with probable internal haemorrhage, and a tubular serpiginous adjacent structure of $62 \times 28 \mathrm{~mm}$, extending into the myometrium, suggestive of a haematosalpinx, were observed (Fig. 1).

A hysteroscopy was performed under general anaesthesia. The intrauterine cavity was full of clots. After washing with continuous flow, a type 0 submucous leiomyoma classified on the basis of the International Federation of Obstetrics and Gynecology (FIGO) was observed in the posterior uterine wall. A resectoscopic excision was performed, and the histopathological examination confirmed the diagnosis of leiomyoma. The patient was referred to our hospital again four years later (aged 55), due to endometrial thickening observed during a pelvic ultrasound. An office hysteroscopy was performed, in which a pediculate polypoid lesion was observed at a similar location to that of the lesion resected in the previous hysteroscopy. The lesion was completed removed, and the histopathological examination revealed a $22 \mathrm{~mm}$ endometrial polyp without atypia. At 56 years of age, the patient returned with postmenopausal uterine bleeding and endometrial thickening. An office hysteroscopy was performed, and a polypoid structure was observed at a similar location to that of the previously excised lesions. A bipolar needle was used. After the first incisions, a viscous and brownish content emerged. After washing the uterine cavity, the lesion had mysteriously disappeared and seemed to have entered a cavity created by the initial incisions. It was necessary to reduce the intrauterine pressure to re- observe the polypoid lesion. This new area was explored and a diverticular cavity with trabeculated-looking walls was observed. There was no active bleeding, and the procedure was interrupted because of the fear of perforation. The histopathological examination revealed fragments of an endometrial polyp with areas of tubal and mucinous metaplasia. The patient underwent a laparoscopic hysterectomy with bilateral salpingo-oophorectomy. On laparoscopic inspection, the uterus and adnexa appeared normal.

Macroscopic examination showed a uterus measuring $86 \times 50 \times 30 \mathrm{~mm}$ and revealed a mass in the right wall of the uterus measuring $75 \times 50 \times 40 \mathrm{~mm}$, involving the serosa, all myometrium, and polypoid growth to the intrauterine cavity (Figs. 2 and 3 ).

Microscopically there were cystic spaces of varying sizes lined by simple cuboidal and ciliated tube-type epithelium. The stroma between the glands and cysts was fibromuscular, with no evidence of endometrial stroma (Fig. 4).

\section{DISCUSSION}

Many reports of endosalpingiosis have been published since it was first described by Sampson (1930). ${ }^{6}$ Thirty two cases of uterine endosalpingiosis were retrieved from the literature by searching the PubMed database and other databases (see Appendix 1: https://www.actamedicaportuguesa.com/revista/index.php/amp/article/view/14292/Appendix_01.pdf).

Macroscopically, endosalpingiosis often appears as a polypoid mass or as multiple cysts of different sizes. The diagnosis of endosalpingiosis is made histologically by the presence of tube-like epithelium containing three types of cells: ciliated columnar cells, non-ciliated columnar secretory mucous cells, and so-called intercalary or peg cells in an ectopic location. ${ }^{4}$

The clinical features of endosalpingiosis vary widely

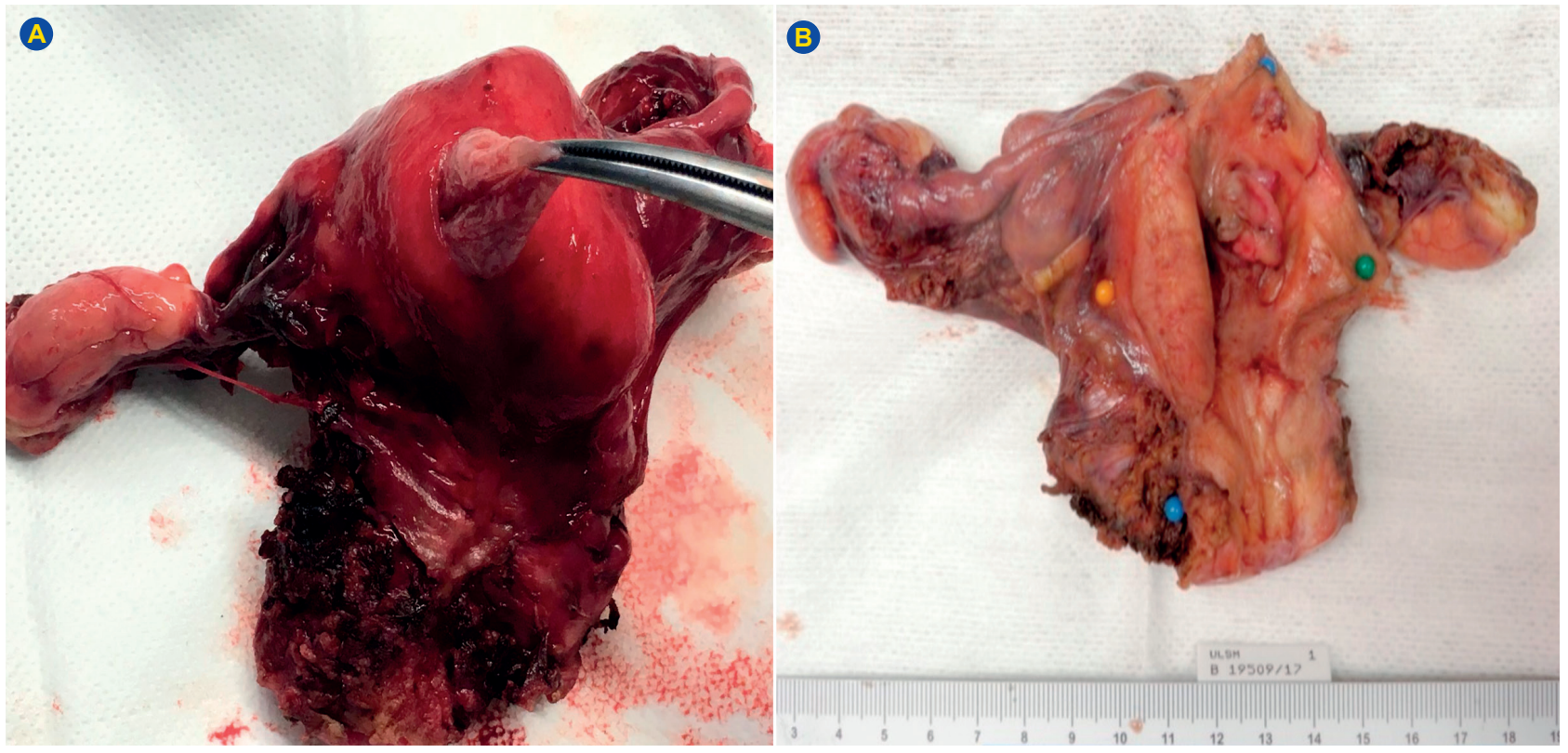

Figure 2 - Macroscopic view. (A) Posterior view of the uterus: Exteriorization with the help of a forceps of a cystic lesion from the diverticular cavity $(B)$ a polypoid cystic lesion, protruding into the endometrial cavity and a tumour-like mass in the lateral wall. 


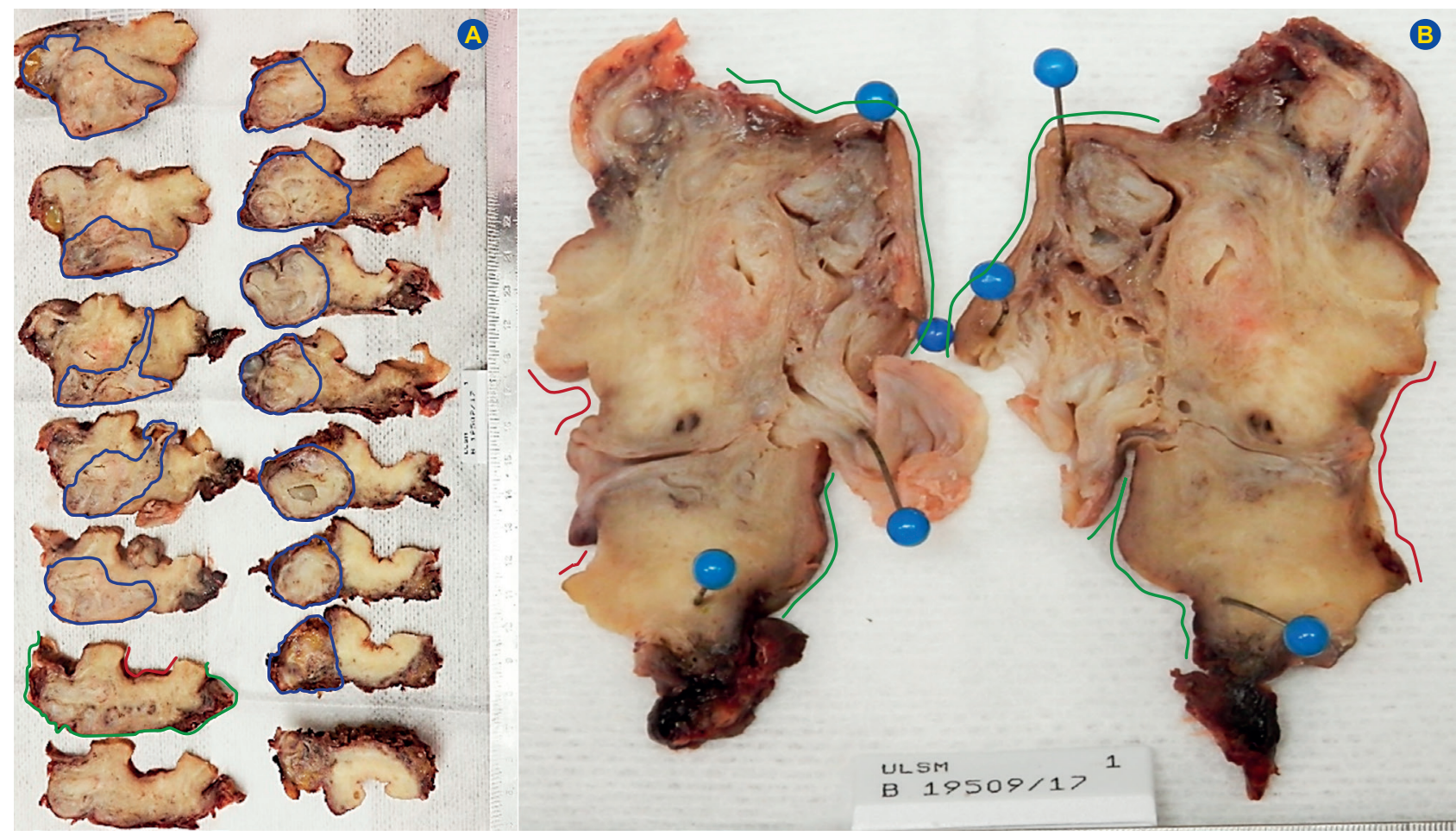

Figure 3 - Macroscopic view, the gross findings. (A) Cut surface showing a solid and cystic tumour-like mass from the serosa to the endometrium and from the uterine fundus (top left) to the cervix (bottom right) ('green line' - serosa of the uterus, 'red line' - endometrium, 'blue lines' - lesion. (B) Solid and cystic tumour-like mass traversing the full thickness of the uterine wall.

depending on the involved organs; it can be asymptomatic and affect women mostly during reproductive age. ${ }^{1}$

We report the first case of uterine FCE diagnosed in a woman with postmenopausal bleeding associated with several unusual hysteroscopic findings. The final diagnosis was only established after hysterectomy.

In the literature, uterine FCE is described as having subserous, intramural or a cervical involvement. Cil et al reported the first case with the involvement of the endometrial cavity. Only in the histopathological examination was continuity with the endometrial cavity discovered.

This is the second case of uterine FCE with an extension into the uterine cavity and it has been the first time to be observed and described during hysteroscopy. ${ }^{7,8}$ The internal aspects of the cystic lesions were observed with some pseudo-diverticular characteristics. Another hysteroscopic pitfall of our case was related to the unusual possibility of an existing condition behind a lesion found and resected during hysteroscopy.

Interestingly, a type 0 submucous leiomyoma and a polyp had also been excised (with histopathological review) a few years prior to the uterine FCE diagnosis. This is quite a unique association of different lesions. After the leiomyoma excision, even without explanation for the ultrasound and magnetic resonance imaging (MRI) findings of intrauterine cystic lesions, the patient was discharged. Four years later, another endometrial thickening appeared. A second hysteroscopy was performed, with the excision of an endometrial polyp at a similar location to that of the previously resected myoma. Once again, clinicians were convinced that the problem had been solved, but probably the polyp excised was covering a co-existing larger transmural uterine cystic lesion.

Such lesions may protrude into the uterine cavity and can be observed in hysteroscopy. Once opened and spontaneously drained of their content, they may become observable, which was seen in the third hysteroscopy. The lesions that appeared as pseudo-diverticula, were in fact pedunculated intracavitary lesions which may have become hidden secondarily to elevated intrauterine pressure. With a decrease in pressure, they can reappear. Moreover, pseudo-diverticula may simulate uterine perforation.

Initially, the patient had perimenopausal uterine bleeding. In the literature, most of these cases of uterine FCE are present in premenopausal women. Only ten cases were discovered in peri/postmenopausal women, like our case. MRI was performed to elucidate pelvic ultrasound findings, and images compatible with uterine FCE were observed, containing an intrauterine formation and a tubular serpiginous adjacent structure extending into the myometrium and to the right para-tubal region. FCE was not considered in the initial differential diagnosis, due to its rarity and because other conditions are more frequently seen in gynaecologic practice, namely adenomyosis, endometrial polyp, leiomyoma and adenocarcinoma. ${ }^{3}$

There is no data to guide the best management of intrauterine FCE. Having never been described before in the context of a hysteroscopy, such a diagnosis would be difficult, if not impossible, to imagine. It can mimic a neoplastic process that can lead to an incorrect preoperative diagnosis 

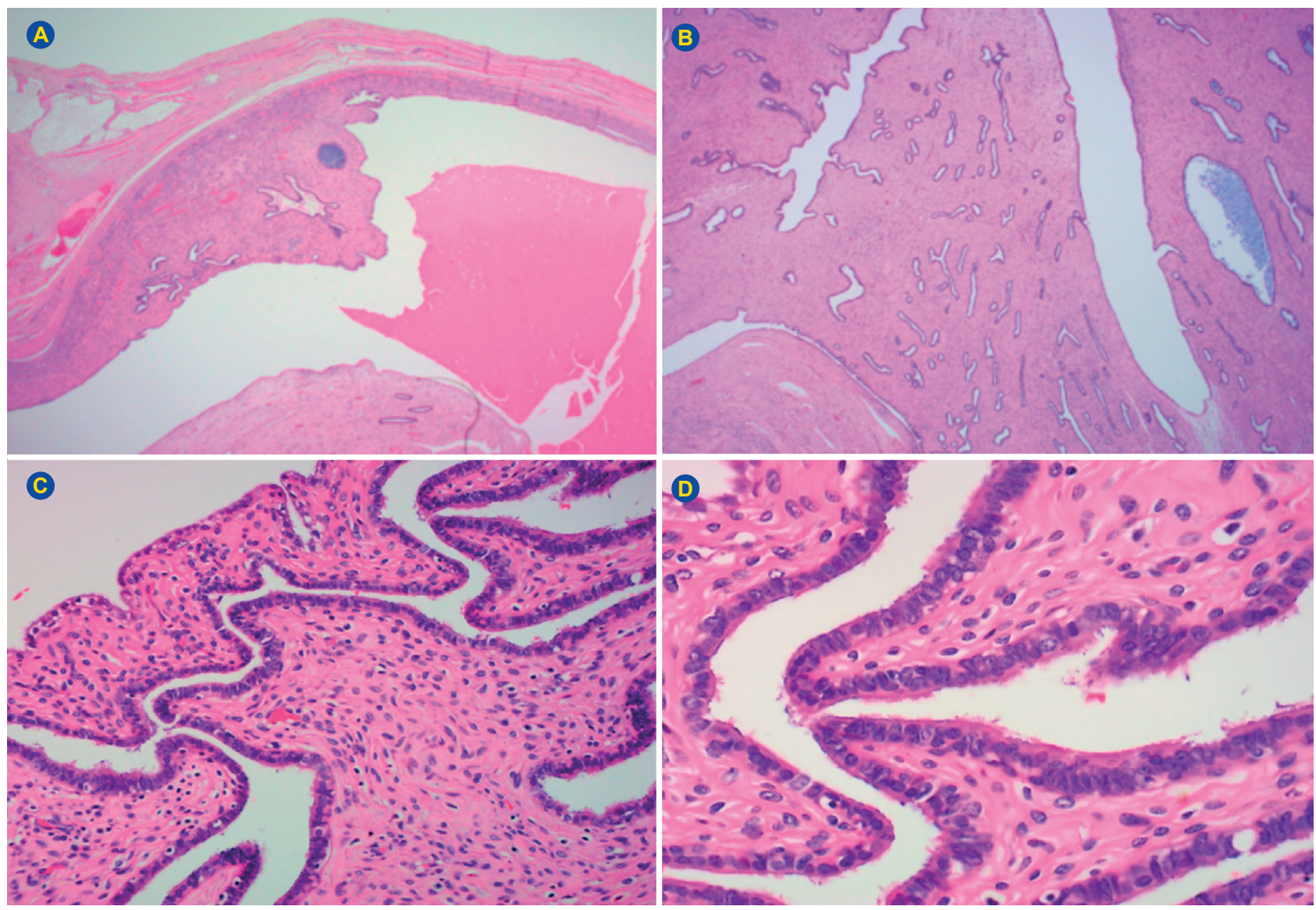

Figure 4 - Microscopic findings. Microscopically there were cystic spaces of varying sizes lined by simple cuboidal and ciliated tube-type epithelium. No cytological atypia was seen. The stroma between the glands and cysts was fibromuscular, with no evidence of endometrial stroma.

and hence possible overtreatment. However, as FCE is a non-malignant process, conservative treatment instead of total hysterectomy is reasonable. A cause for concern is that the probability of uterine and ovarian cancers is significantly increased in women with endosalpingiosis, especially in premenopausal women. An association between endosalpingiosis and clear cell and mucinous ovarian carcinomas has been observed, but there is no evidence supporting oophorectomy at the completion of fertility in patients with known endosalpingiosis (except for serous tumours). ${ }^{9,10}$

\section{CONCLUSION}

FCE is a rare condition that may be associated with several pitfalls which complicate hysteroscopic visualization of the condition, namely lesions behind lesions, hidden lesions, and simulation of uterine perforation, as in our case.

\section{AUTHORS CONTRIBUTION}

$\mathrm{CP}$ : Conception of the work, first draft, critical review and copedit of the paper, corresponding author and fcritical review and final approval of the version to be published

RMN, ACS, TA: Acquisition of images, interpretation and description of the figures.

PTS, JB: Conception of the work, critical review and final approval of the version to be published.

\section{PROTECTION OF HUMANS AND ANIMALS}

The authors declare that the procedures were followed according to the regulations established by the Clinical Research and Ethics Committee and to the 2013 Helsinki Declaration of the World Medical Association.

\section{DATA CONFIDENTIALITY}

The authors declare having followed the protocols in use at their working center regarding patients' data publication.

\section{PATIENT CONSENT}

\section{Obtained.}

\section{COMPETING INTERESTS}

The authors have declared that no competing interests exist.

\section{FUNDING SOURCES}

This research received no specific grant from any funding agency in the public, commercial, or not-for-profit sectors. 


\section{REFERENCES}

1. Zangmo R, Singh N, Kumar S, Vatsa R. Second look of endosalpingiosis: a rare entity. J Obstet Gynecol India. 2017;67:299-301.

2. Singh N, Murali S, Zangmo R. Florid cystic endosalpingiosis, masquerading as malignancy in a young patient: a brief review. BMJ Case Rep. 2014;2014:bcr2013201645.

3. Kajo K, Žúbor P, Macháleková K, Plank L, Višňovský J. Tumor-like manifestation of endosalpingiosis in uterus: a case report. Pathol Res Pract. 2005;201:527-30.

4. Ong N, Maher P, Pyman J, Readman E, Gordon S. Endosalpingiosis, an unrecognized condition: report and literature review. Gynecol Surg. 2004;1:11-4.

5. Habiba M, Brosens I, Benagiano G. Müllerianosis, endocervicosis, and endosalpingiosis of the urinary tract: a literature review. Reprod Sci. 2018;25:1607-18.
6. Sampson JA. Postsalpingectomy endometriosis (endosalpingiosis). Am J Obstet Gynecol. 1930;20:443-80.

7. Cil AP, Atasoy P, Kara SA. Myometrial involvement of tumor-like cystic endosalpingiosis: A rare entity. Ultrasound Obstet Gynecol. 2008;32:10610.

8. Suárez-Vilela D, Miguel Izquierdo-García F, Méndez-Alvarez JR, Domínguez-Iglesias F. Florid cystic endosalpingiosis inside a uterine subserous leiomyoma. Pathology. 2009;41:401-3.

9. Nixon KE, Schoolmeester JK, Bakkum-Gamez JN. Florid cystic endosalpingiosis with uterine preservation and successful assisted reproductive therapy. Gynecol Oncol Reports. 2018;25:8-10.

10. Esselen KM, Terry KL, Samuel A, Elias KM, Davis M, Welch WR, et al. Endosalpingiosis: more than just an incidental finding at the time of gynecologic surgery? Gynecol Oncol. 2016;142:255-60. 